\title{
Upper Digestive Endoscopic Lesions in Chronic Kidney Disease (CKD): Experience of a Senegalese Center; About 50 Cases
}

Cisse Mouhamadou Moustapha ${ }^{1 *}$, Ka El Hadji Fary ${ }^{1}$, Dia Daouda ${ }^{2}$, Mahamat AG $^{1}$, Jean De Dieu Nzambaza ${ }^{1}$, Lemrabott Ahmed Tall ${ }^{1}$, Fall Seynabou ${ }^{3}$, Faye Maria', Fall Khodia', Bassene Marie Louise ${ }^{4}$, Niang Abdou' ${ }^{1}$ and Diouf Boucar ${ }^{1}$ ${ }^{1}$ Department of Nephrology, Cheikh Anta Diop University Teaching Hospital, Aristide Le Dantec, Dakar Senegal

${ }^{2}$ Department of Gastroenterology, Cheikh Anta Diop University Teaching Hospital, Yoff, Senegal

${ }^{3}$ Department of Internal Medicine, Cheikh Anta Diop University Teaching Hospital, Aristide Le Dantec, Dakar, Senegal

${ }^{4}$ Department of Gastroenterology, Cheikh Anta Diop University Teaching Hospital, Aristide le Dantec de Dakar Senegal

\begin{abstract}
Objectives: This study was conducted to evaluate upper digestive endoscopic lesions among patients with chronic kidney disease.

Methodology: We conducted a retrospective cross-sectional study in Nephrology and Gastroenterology services at Hospital Center University Aristide Le Dantec from January 2008 to December 2009. All patients with chronic kidney disease who underwent an upper gastrointestinal endoscopy were included.

Results: Fifty patients were included, with a mean age of 44.2 years and a sex ratio (male/female) of 1.27. Upper digestive endoscopy was abnormal in $76 \%$. Peptic esophagitis was noted in 7 patients, hiatal hernia in 10 and cardial incontinence in 2. Congestive gastritis was observed in 6 cases, followed by erosive and hemorrhagic gastritis in 5 cases each one and a gastric ulcer in 2. Six patients presented a bulbitis, which was erosive in 3 , congestive in 2 and 1 of the large folds. Bulbar ulcer was noted in 3 patients and post bulbar ulcer was also noted in 3 patients. One patient presented a congestive duodenitis.
\end{abstract}

Conclusion: Upper digestive endoscopy lesions are frequent and diverse among patients with chronic kidney disease. These finding justify the systematization of upper digestive endoscopy in digestive complaining uremic patients.

Keywords: Chronic kidney disease, Hemodialysis, Upper gastrointestinal endoscopy

\section{Introduction}

Gastrointestinal symptoms revealing or complicating chronic kidney disease (CKD) are very numerous [1]. Different gastroesophageal and gastroduodenal endoscopic lesions are described in CKD with a predominance of gastritis [2]. Our objective was to report the anomalies found at upper gastrointestinal endoscopy (UGE) in patients with CKD in nephrology unit in Dakar.

\section{Patients and Methods}

This was a retrospective cross-sectional study, conducted in the Nephrology unit of the Aristide Le Dantec Hospital in Dakar from January 2008 to December 2009. The records of CKD patients hospitalized who underwent UGE were collected. In these cases, we collected age, sex, history, the stage of $\mathrm{CKD}$, digestive symptoms that led UDE and lesions found. Incomplete records were excluded. The estimated creatinine clearance was calculated using the Cockcroft and Gault. CKD was defined as a creatinine clearance below $60 \mathrm{ml} /$ $\min / 1.73 \mathrm{~m}^{2}$ for at least three months and the classification used was that proposed by K-DIGO [3]. The data were entered and analyzed using SPSS 13.0 software. The difference was considered significant if $\mathrm{p}$ value was $<0.05$.

\section{Results}

We collected 65 cases, 15 were excluded and analyses focused on the remaining 50 cases. The average age of patients was 44 years (range from 17 to 81 years); there were 28 men and 22 women (sex ratio, 1.27). The mean creatinine clearance was $8.54 \mathrm{ml} / \mathrm{min}$ (range 2.61 and $34.60 \mathrm{ml} / \mathrm{min}$ ). Forty-five patients were CKD stage 5, three were CKD stage 4 and 2 were CKD stage 3. Thirteen patients (26\%) were receiving renal replacement therapy with 10 using hemodialysis and 3 peritoneal dialysis. Gastrotoxic medication with aspirin and/or nonsteroidal anti-inflammatory drugs was found in 27 patients (54\%), active smoking in 10 patients weaned and regular alcohol consumption in 2 patients. The causes of CKD were diabetic nephropathy (5 cases), hypertensive nephropathy (21 cases), primitive glomerulonephritis (9 cases), chronic tubulointerstitial nephropathy (9 cases), sickle cell nephropathy (1 case), autosomal dominant polycystic kidney disease (1 case) and undetermined nephropathy (4 cases).

The symptoms that led UGE are shown in Table 1.

UGE revealed lesions in 38 cases (76\%) and these are shown in Table 2.

In analytical studying, endoscopic lesions were not correlated with the stages of CKD or the existence or not of renal replacement therapy.

\section{Discussion}

This study highlights the high prevalence of upper gastrointestinal endoscopic lesions in patients with CKD (76\%). A prevalence of $72.9 \%$ was found by Serme et al. in Burkina Faso [4] and in Italy it was 74\% according to Nardone et al. [5] Upper gastrointestinal lesions in our series had a predominant localization in gastric and duodenal level. The

*Corresponding author: Cisse Mouhamadou Moustapha, Hospital Center University Aristide Le Dantec, 30 avenues, Pasteur Dakar, Sénégal, BP 3001, Tel: +00 2217757388 09, E-mail: mhmcisse@yahoo.fr

Received: November 21, 2014; Accepted: May 14, 2015; Published: May 21 2015

Citation: Cisse MM, Fary KEH, Daouda D, Mahamat AG, Nzambaza JDD, et al (2015) Upper Digestive Endoscopic Lesions in Chronic Kidney Disease (CKD): Experience of a Senegalese Center; About 50 Cases. J Nephrol Ther 5: 202 doi:10.4172/2161-0959.1000202

Copyright: $\odot 2015$ Cisse MM ,et al. This is an open-access article distributed under the terms of the Creative Commons Attribution License, which permits unrestricted use, distribution, and reproduction in any medium, provided the original author and source are credited. 
Citation: Cisse MM, Fary KEH, Daouda D, Mahamat AG, Nzambaza JDD, et al. (2015) Upper Digestive Endoscopic Lesions in Chronic Kidney Disease (CKD): Experience of a Senegalese Center; About 50 Cases. J Nephrol Ther 5: 202. doi:10.4172/2161-0959.1000202

Page 2 of 2

\begin{tabular}{|c|c|c|}
\hline Indications & Number of patients & Percentage (\%) \\
\hline Vomiting & 42 & 84 \\
\hline Anorexia & 32 & 64 \\
\hline Nausea & 24 & 48 \\
\hline Epigastric pain & 23 & 46 \\
\hline Regurgitation & 20 & 40 \\
\hline Dyspepsia & 16 & 32 \\
\hline Heartburn & 11 & 22 \\
\hline Dysphagia & 6 & 12 \\
\hline Hematemesis & 6 & 12 \\
\hline
\end{tabular}

Table 1: Indications of UGE.

\begin{tabular}{|c|c|c|c|}
\hline \multirow{3}{*}{ Esophagus } & Lesions & $\begin{array}{c}\text { Number of } \\
\text { patient }\end{array}$ & $\begin{array}{c}\text { Percentage } \\
\text { (\%) }\end{array}$ \\
\cline { 2 - 4 } & Peptic oesophagitis & 8 & 16 \\
\cline { 2 - 4 } & Sliding hiatal hernia & 10 & 20 \\
\hline \multirow{3}{*}{ Stomach } & Schatzki ring & 1 & 2 \\
\cline { 2 - 4 } & Gastritis & 17 & 34 \\
\cline { 2 - 4 } & Gastriculcer & 2 & 4 \\
\hline \multirow{2}{*}{ Duodenum } & Angiodysplasia & 1 & 14 \\
\cline { 2 - 4 } & Bulbitis & 7 & 6 \\
\hline
\end{tabular}

Table 2: Lesions on UGE.

most common gastric lesions in our patients were gastritis. In Burkina Faso, gastric lesions were at the forefront followed with $68.7 \%$ of cases by duodenal lesions with $32.2 \%$ of cases [4]. Several factors, including alcohol, sepsis, hypergastrinemia and gastrotoxic drugs have been implicated in the development of gastritis [5]. The degree of chronic kidney disease was not correlated with the occurrence of gastric lesions. However, the influence of the degree of CKD on the occurrence of gastritis is variously appreciated. Stolic did not find influence while Mitchell found gastritis in all patients with severe stages of CKD $[6,7]$. Gastritis often noted in uremic patients, has often been reported to cause bleeding $[8,9]$. As in our series, the prevalence of angiodysplasia is relatively rare [5]. By Goldstein against reported a high frequency of angiodysplasia lesions in severe uremia [10]. Angiodysplastic lesions are the leading cause of gastrointestinal bleeding in patients with CKD according Zukerman [11]. Duodenitis was rare in our series. This corroborates the results of Al Mueilo in Saudi Arabia who found only 3 duodenitis (5.2\%) in 54 hemodialysis patients [12]. In duodenum, ulcer was equally divided between the duodenal bulb and the other portions. This distribution is different from classical literature data, which show a predilection site of ulcer on the post bulbar area. These ulcers are often multiple [13]. Work performed at the Hospital Al-Khobar Saudi

Arabia found a hiatal hernia in $2.5 \%$ of patients with end-stage CKD [13]. The reflux esophagitis accounted for $18 \%$ of endoscopic lesions. Its prevalence is $26.2 \%$ in CKD [14].

\section{Conclusion}

Upper gastrointestinal lesions often overlooked in this field can lead to major complications, the most feared is bleeding. This work shows the need for an upper endoscopy in patients with digestive uremic signs.

\section{Reference}

1. Kang JY (1993) The gastrointestinal tract in uremia. Dig Dis Sci 38: 257-268.

2. Verma PP, Pruthi HS, Thakur SK, Prasher PK, Singh B, et al. (1999) upper gastrointestinal mucosa in chronic renal failure: an endoscopic and histological evaluation. Med J Armed Forces India 55: 307-309.

3. Levey AS, Eckardt KU, Tsukamoto $\mathrm{Y}$, Levin A, Coresh $\mathrm{J}$ et al. Definition and classification of kidney disease: a position statement from kidney disease: improving global outcomes (KDIGO). Kidney Int 67: 2089-2100.

4. Serme AK, Lengani A, Ilboudo PD, Sawadogo N, Sombie R (2003) Les lésions endoscopiques digestives hautes dans l'insuffisance rénale chronique sévère en Afrique. Med Afr Noire 50: 31-36.

5. Nardone G, Rocco A, Fiorillo M, Del Pezzo M, Autiero G, et al. (2005) Gastroduodenal lesions and Helicobacter Pylori infection in dyspeptic patients with and without chronic renal failure. Helicobacter 10: 53-58.

6. Mitchell CJ, Jewell DP, Lewin MR, McLaughlin JE, Moorhead JF (1979) J Clin Pathol 32: 208-213.

7. Stolic RV, Jovanovic AN, Zivic ZP, Peric VM, Markovic SR, et al. (2008) Influence of the level of renal insufficiency on endoscopic changes in the upper gastrointestinal tract. Am J Med Sci 1: 39-43.

8. Khedmat $\mathrm{H}$, Ahmadzad-AsI $\mathrm{M}$, Amini $\mathrm{M}$, Lessan-Pezeshki $\mathrm{M}$, Einollahi $\mathrm{B}$, et al. (2007) Gastroduodenal lesions and helicobacter pylori infection in uremic patients and renal transplant recipients. Transplant Proc 39: 1003-1007.

9. Tsai CJ, Hwang JC (1996) Investigation of upper gastrointestinal hemorrage in chronic renal failure. J Clin Gastroenterol 22: 2-5.

10. Goldstein H, Murphey D, SokolA, Rubini ME (1967) Gastric acid secretion in patients undergoing chronic dialysis. Arch Inter Med 120: 645-653.

11. Zukerman GL, Cornette GL, Clouse RE, Harter HR (1985) upper gastrointestinal bleeding in patients with chronic renal failure. Ann Intern Med 102: 588-592.

12. Al Mueilo SH (2004) Gastroduodenal lesions and helicobacter pylori infection in hemodialysis patients. Saudi Med Journ 25: 1010-1014.

13. Fallone CA, Mayrand S (2001) Gastrooesophageal reflux and hyperacidity in chronic renal failure. Perit Dial Int 21: S295-299.

14. Cekin AH, Boyacioglu S, Gursoy M, Bilezikci B, Gur G, et al. (2002) Gastroesophageal reflux disease in chronic renal failure patients with upper gastrointestinal symptoms: multivariate analysis of pathogenesis factors. Am J Gastroenterol 97: 1352-1356 